\title{
Psychosocial Impact of Early Pregnancy: Case of 95 Students in the City of Abidjan
}

\author{
Aka Rita Ahou ${ }^{1,}$, Traore Brahim Samuel ${ }^{1}$, Konan Koffi Paulin², \\ Yeo-Tenena Yessonguilana Jean-Marie ${ }^{1}$ \\ ${ }^{1}$ Medical Sciences Training and Research Unit, Felix Houphouet Boigny University, Abidjan, Ivory Coast \\ ${ }^{2}$ Addiction and Mental Hygiene Service, National Institute of Public Health, Abidjan, Ivory Coast \\ Email address: \\ rita_aka@yahoo.fr (A. R. Ahou), samygrande@live.fr (T. B. Samuel), kk420408@gmail.com (K. K. Paulin), \\ ouandete@gmail.com (Yeo-Tenena Y. Jean-Marie) \\ ${ }^{*}$ Corresponding author
}

\section{To cite this article:}

Aka Rita Ahou, Traore Brahim Samuel, Konan Koffi Paulin, Yeo-Tenena Yessonguilana Jean-Marie. Psychosocial Impact of Early Pregnancy: Case of 95 Students in the City of Abidjan. American Journal of Psychiatry and Neuroscience. Vol. 9, No. 3, 2021, pp. 126-129.

doi: 10.11648/j.ajpn.20210903.19

Received: July 4, 2021; Accepted: July 16, 2021; Published: September 4, 2021

\begin{abstract}
Pregnancy is an accomplishment in many cases. However, when it occurs early especially during schooling, it can be an obstacle to the development of adolescent girls, with a significant psychosocial impact. In Côte d'Ivoire, more than 4000 cases of school pregnancy were reported in 2017. The objective of this study was to describe the psychosocial impact of early pregnancy among selected students in the commune of Abidjan. We conducted a cross-sectional, descriptive study of adolescent girls who visited the health centers for their pre- or post-natal consultation. A total of 95 girls were included in our study. Of these, 53.68\% were in their first cycle of secondary school. More than half, i.e. $52.63 \%$, were between 12 and 17 years of age, and $91 \%$ were primigravida. Pregnancies were mostly unwanted (83\%), while almost all sexual intercourse was consensual and unprotected. The occurrence of pregnancy had a negative psychosocial impact that manifested itself emotionally through a painful experience. Indeed, $66.07 \%$ of the girls considered abortion as soon as the pregnancy was announced. In $33.3 \%$ of cases, the abortion attempts were successful. The emotional state of these students was marked by feelings of discouragement, self-deprecation with lowered self-esteem, guilt and shame in 53\%; $47.36 \% ; 28.42 \%$ and $21.05 \%$ respectively. Sub-depressive states were also recorded in $31.58 \%$ of the students, manifested by insomnia, anorexia and sadness with crying. At school level, a drop in performance was noted in 58.95\% of cases, and $22.10 \%$ dropped out. As for social relations, they were marked by the genesis of conflicts leading to abandonment both at the family level and from the perpetrators of the pregnancy in respectively $31.58 \%$ and $32.63 \%$. In light of the above, it is clear that the occurrence of an adolescent pregnancy while in school has a negative psychological, educational and social impact.
\end{abstract}

Keywords: Early Pregnancy, Psychological Experience, Students, Abidjan

\section{Introduction}

Pregnancy is a physiological process that leads to both physical and psychological disturbances. In many cases, it contributes to the blossoming of femininity, leading to a feeling of accomplishment and happiness. However, it can be a hindrance to the development of young girls with a significant psychosocial impact on both the mother and the child, especially when it occurs during schooling. [1, 2]

Pregnancies among young girls during schooling, generally unwanted, are recurrent. This state of affairs is a concern for all societies. Moreover, the World Health Organization has stated that nearly 16 million adolescents between the ages of 15 and 19 give birth each year in the world [3]. Most of the studies that have been carried out on this topic to date have focused on the strategies to be implemented to curb this phenomenon. Despite their relevance, they ignore the psycho-social situation of pregnant students or student-mothers, most of whom have difficulty adapting. In addition, early pregnancy may reveal a pre-existing psycho-social fragility related to the living environment $[4,5]$. Adolescent pregnancy can therefore be a 
source of isolation, precariousness, and psycho-affective and social problems.

In short, it constitutes a handicap that very often worsens the living conditions of young girls [6].

In sub-Saharan Africa, almost all pregnant adolescents have often been forced to postpone their schooling [7]. Several studies have shown that motherhood reduces a girl's chances of continuing and completing secondary school by 24-37\% [2, 6-8].

Furthermore, according to a WHO report, pregnancyrelated complications are among the leading causes of death among girls aged 15 to 19 in sub-Saharan Africa [3].

These findings led us to examine the psychological experiences of young girls who have become pregnant while in school.

\section{Methodology}

We conducted a prospective cross-sectional study in three hospitals: the Urban Health Unit (UHU) of AboboDoumé/Locodjro, the General Hospital of Adjamé, and the General Hospital of Abobo-Sud.

For this study, we used the purposive sampling technique.

The following were included

Female students,

Students who were pregnant or had recently given birth

Students who agreed to participate in the study.

The respect of these criteria allowed us to obtain a sample of 95 girls who were pregnant or had recently given birth.

Data collection for this study was based on a questionnaire developed for this purpose and administered during a semidirective interview to the students.

The questionnaire was pretested to make it more comprehensive and objective before administration.

\section{Results}

\subsection{Socio-demographic Characteristics}

More than half $(52.63 \%)$ of our respondents had become pregnant during adolescence, i.e. before the age of 19. Most of them were primigravida (91\%) and $53.68 \%$ had become pregnant during their first cycle of secondary school (6th-3rd grade). It was noted that $28 \%$ of the girls were married; the others were single. Most students, $90.52 \%$, were still under the care of a parent or guardian.

\subsection{Characteristics of Sexual Intercourse}

Table 1. Nature of sexual relations and desire for pregnancy among our respondents.

\begin{tabular}{lcll}
\hline Nature of sexual relations and desire & \multicolumn{2}{c}{ Respondents' answers } \\
\cline { 2 - 4 } for pregnancy among our respondents & $\mathbf{N}$ & $\mathbf{\%}$ \\
\hline Nature of sexual & Consented & 94 & 98,95 \\
relations & Not consented & 01 & 1,05 \\
& Yes & 06 & 16,84 \\
Pregnancy desire & No & 79 & 83,16 \\
Total & & 95 & 100 \\
\hline
\end{tabular}

Few girls $(3.16 \%)$ used contraceptive methods; condoms were the only contraceptive method used by our respondents. The reasons given for the under-use of contraceptive methods included lack of convenience for condoms and lack of knowledge and/or affordability for other methods.

Only $6.31 \%$ of the respondents were having their first sexual experience.

\subsection{Psychological and Social Impacts of Pregnancy}

The onset of pregnancy had a negative psychosocial impact that manifested itself emotionally through a painful experience. In fact, $66.07 \%$ of the girls considered an abortion as soon as the pregnancy was announced. In $33.3 \%$ of cases, the abortion attempts were successful. The main reaction of the girls to the announcement of the pregnancy was Discouragement, selfdeprecation with lowered self-esteem, guilt and shame in 53\%; $47.36 \% ; 28.42 \%$ and $21.05 \%$ respectively. Subdepressive states were also recorded in $31.58 \%$ of the students, manifested by insomnia, anorexia and sadness with crying.

Following the announcement of the pregnancy, there was a reshuffling of the relationship between parents and their children. Indeed, in $44.21 \%$ of cases, family relations became conflictual, and in $31.58 \%$ of cases, the children were abandoned or rejected.

As for the authors of the pregnancies, only $29.47 \%$ reacted favorably to the announcement of the pregnancy, thus reinforcing the moral and financial support given to pregnant students. In $37.90 \%$, conflictual relationships were observed and in $32.63 \%$, reactions of rejection and abandonment.

Table 2. Professional status and reactions of the author of pregnancies.

\begin{tabular}{llll}
\hline \multirow{2}{*}{ attitude of the author of the pregnancy } & \multicolumn{2}{l}{ Respondents' answers } \\
\cline { 3 - 4 } & & $\mathbf{N}$ & $\mathbf{\%}$ \\
\hline \multirow{2}{*}{$\begin{array}{lll}\text { Professional status } \\
\text { of the author of the }\end{array}$} & Students & 41 & 43,16 \\
pregnancy & Sans employ & 17 & 17,89 \\
& Working class & 26 & 27,37 \\
\multirow{2}{*}{$\begin{array}{l}\text { Reaction of author } \\
\text { of the pregnancy }\end{array}$} & Supervisor & 11 & 11,58 \\
\multirow{2}{*}{ Total } & Reject & 31 & 32,63 \\
\hline
\end{tabular}

\subsection{Socioeconomic and Educational Impacts of Pregnancy on Young Girls}

In terms of financial support, it came mainly from the parents and relatives of the respondents (86.42\%). Only $13.58 \%$ of the girls managed to support themselves with or without the help of the person who caused the pregnancy. It was also noted that $60 \%$ of our respondents felt that the financial support they received was insufficient.

The pregnancy had a negative impact on the girls' schooling. In $58.95 \%$ of cases, this impact was expressed in terms of a drop in school performance, while $22.10 \%$ of the respondents had dropped out of school. Following their experiences of pregnancy during schooling, $61 \%$ of the girls said they had feelings of regret. 


\section{Discussion}

\subsection{Sociodemographic Characteristics}

Early pregnancies in schools are a concern worldwide [3]. In our country, the Ministry of National Education, Technical Education and Vocational Training (MENETFP) counted 4137 and 4475 pregnancies respectively during the 20162017 and 2017-2018 school years in the secondary cycle [9].

In our study more than half of the respondents were between 12 and 17 years old, i.e., they were minors. Most of them were in their first cycle of secondary school. Although they were biologically able to conceive, they were not yet socially and financially autonomous. Indeed, the majority of the students were single and almost all of them were still under the care of a parent or guardian. These different findings raise several questions, in particular that of sex education among adolescents, which remains problematic for various reasons: lack of communication between parents and children, lack of information, and the fact that the subject is still considered "taboo" in some countries $[2,10]$.

In addition, sexual violence committed by teachers, early marriages, bad company, the influence of friends, and following are other factors that may be at the origin of this phenomenon $[2,3,10]$.

\subsection{Characteristics of Sexual Intercourse}

Our study showed that $83 \%$ of pregnancies were unwanted, while almost all sexual intercourse was consensual and unprotected. The majority of students were not having sex for the first time. Our results corroborate several studies that emphasize that the sexual act in adolescents can be used, among other things, to fulfill emotional needs, affirm femininity/virility, and express affection. These facts could then justify the precocity of intercourse, the absence of planning and the multiplicity of sexual partners observed in them. [5]

Few respondents used contraceptive methods. This resistance to contraception can be explained in two ways:

lack of adherence to condoms in general

Lack of knowledge and/or financial inaccessibility of other contraceptive methods.

In addition to the risk of pregnancy, these young people were also exposed to sexually transmitted infections (STIs).

If physically, the teenager has the possibility to perform the sexual act, a question remains. It is a question of "responsible" sexuality.

\subsection{Psychological and Social Impacts of Pregnancy on Young Women}

The results of our study showed that as soon as the pregnancy was announced, the reactions observed among the interviewees were negative. This finding is not surprising when we know that for the majority of them, the pregnancy was unwanted and occurred at an early age and in conditions of social insecurity. Pregnancy therefore caused disturbances in the psychological well-being of these girls. These results are in line with other studies which maintain that the announcement of any unwanted pregnancy, whatever the context of its occurrence, has a negative psychological impact on the mother and even on her entourage $[7,8,11]$.

The current pregnancy was therefore perceived as a hindrance to their psycho-social development, especially since it was a source of conflict between the girls and their parents, even to the point of abandonment for some of them. This is probably one of the reasons that led $66.07 \%$ of them to consider abortion. This state of affairs is described in the literature. However, Fournier et al found an improvement in family relations after childbirth [12]. This aspect was not investigated in our study.

In some of the women interviewed, this psycho-social distress was accentuated by the irresponsibility and immaturity of the father, both psycho-social and financial. In fact, the latter either refused the paternity of the pregnancy or secondarily abandoned the adolescents. In this regard, several studies indicate that social relationships, especially with the father of the child, are problematic for pregnant students [3, 4, 13].

Parental assistance and support from the perpetrators of these pregnancies was lacking or absent in the majority of them. According to Opadou, this assistance is the basis of social support, and girl-mothers who receive it are less exposed to psycho-social risk factors [14].

\subsection{Socioeconomic and Educational Impacts of Pregnancy on Young Girls}

School dropout, a major consequence of pregnancy in the school environment, affected $22.1 \%$ of our population. Several studies are unanimous on this fact, which could be justified by the lack of financial means to assume both the expenses inherent to pregnancy and school fees, especially in developing countries. The material needs increase considerably with pregnancy and after the birth of the child, many young students are forced to abandon their studies in order to carry out activities to provide for their families. Thus, teenage motherhood reduces the chances of further education, employment, and increases the risk of being a single parent and living in constant poverty [2-8].

However, we noted that more than half of the respondents were able to continue their studies while experiencing a decline in their academic performance; the major challenge for pregnant students or student mothers was to reconcile their studies with their new status $[2,15]$.

Taking into account all these difficulties arising from the advent of pregnancy during schooling, all the students in our study experienced feelings of regret.

\section{Conclusion}

Early pregnancy among students remains a problem in the Ivorian school environment. The results of our study show that despite the actions taken by the authorities in our country, particularly the Ministry of Education, the phenomenon persists. It is therefore essential that government authorities, 
partners and families combine their efforts to find appropriate solutions.

If advocating sexual abstinence until marriage seems difficult to apply nowadays, prevention and information remain a priority for adolescents. It is therefore important that:

Sex education should be taught to them without taboos, both in school and in the family, taking into account their age and level of education.

Reliable information on contraceptive methods is given to them, while making them easily accessible.

Young pregnant students benefit from provisions to maintain their schooling, to reinforce socio-familial support, to promote social and school reintegration in particular and to have access to appropriate medical care.

\section{References}

[1] Dagnogo GB. Pregnancy in schools through the lens of communication for behavior change. Dissertation in the Department of Sociology Alassane Ouattara University; 2014.

[2] Kouakou BJP, Konan AT. Determinants and impacts of early pregnancy in Ivorian schools. International Journal of Advanced Education and Research; 2018. Vol 3 (1); p 47-53.

[3] WHO 2018. Adolescent pregnancy. Key facts 2018. https://www.who.int/fr/news-room/factsheets/detail/adolescent-pregnancy (Accessed 07/07/2020).

[4] Goyette M, Mann-Feder V, Turcotte M-E, Pontbriand A, Corneau M, Royer M-N. Young women at risk of early motherhood and young pregnant or parenting women from youth centers: their profile, their future and avenues of intervention to support their transition to adulthood. http://archives.enap.ca/bibliotheques/2012/01/030277548.pdf (consulted on 30/07/2020).

[5] Berrewaerts J, Noirhomme-Renard F. Teenage pregnacies: what are the explanatory factors identified in the literature? Wolume-Saint-Lambert (Belgium): Catholic University of Louvain-Reso. 2006. Ref: 06-40.
[6] UNFPA. Study on school pregnancies in Burundi, 2013 report. https://burundi.unfpa.org/sites/default/files/resource-pdf/ (accessed July 07, 2020).

[7] Mbow F, Diop N, Diop AD, Tounkara AC, and Ba SD. "The experience of women with unwanted pregnancies in Senegal: A qualitative study," STEP UP Research Report. Dakar: Population Council. 2016.

[8] Guigma-Diasso MMG. The problem of unwanted pregnancies and the situation of girl mothers in Africa and in the world: Draft report document $\mathrm{n}^{\circ} 16$ session of the parliamentary assembly of the francophonie, Abidjan, 9-12 July 2013, 9p.

[9] Young Africa and AFP. Côte d'Ivoire facing the persistent phenomenon of school pregnancies 2017. https://www.jeuneafrique.com/441506/societe/ivory (accessed $7 / 30 / 2020)$.

[10] UNESCO 2018. Revised edition. International guidelines on sexuality education. An evidence-based approach.

[11] Lochard G. Mental health of pregnant women and child development. Psychology and behavior. Pierre and Marie Curie University - Paris VI, 2014. French. NNT: 2014PA066413.

[12] Fournier J, Marechal J, Siegfried D. Adolescent mother in Geneva: which path, which support? University of Geneva Community Immersion. June 2012. $\mathrm{http}: / /$ www.medecine.unige.ch/enseignement/apprentissage/m odule4/immersion/archives/2011_2012/rapports/Rapport_Mer e_adolescente.pdf (accessed on 30/07/2020).

[13] Deslauriers, J.-M. (2010). The experience of future young fathers during the prenatal period. Reflections, 16 (1), 63-100.

[14] Opadou K. Support deficits and psychosocial adjustment difficulties among student mothers in Abidjan. European Scientific Journal December 2015 edition vol. 11, No. 35 ISSN: $1857-7881$.

[15] Molgat, M. \& Ringuet, C. (2004). From predictability to diversity of pathways? The case of young mothers who have abandoned their studies. Service social, 51 (1), 60-77. 